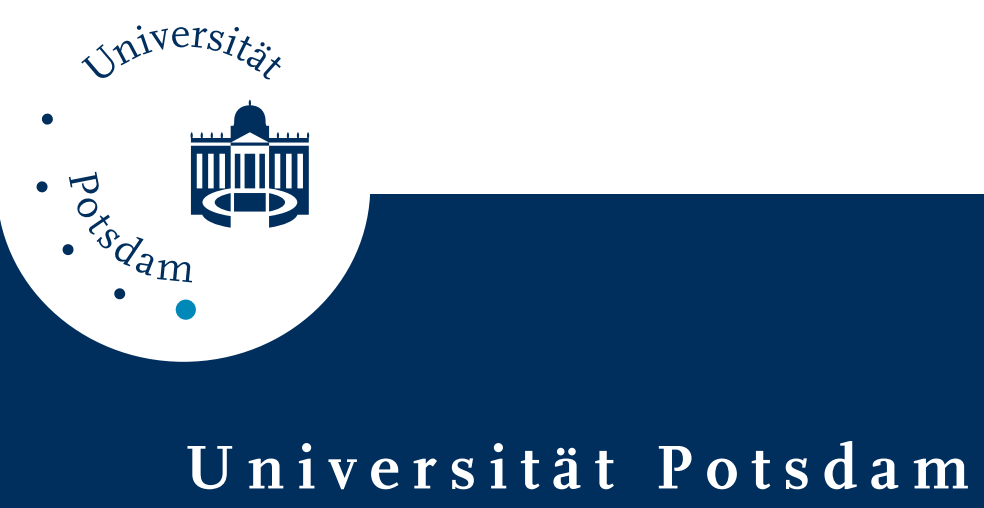

Hanna Lohren | Julia Bornhorst | Hans-Joachim Galla | Tanja Schwerdtle

The blood-cerebrospinal fluid barrier - first evidence for an active transport of organic mercury compounds out of the brain

First published in:

Metallomics, Io (2015) 7, S. I420-I430

DOI http://dx.doi.org/Io.I039/C5MTooI7ID

Postprint published at the Institutional Repository of the Potsdam University:

In: Postprints der Universität Potsdam

Mathematisch-Naturwissenschaftliche Reihe ; 200

http://nbn-resolving.de/urn:nbn:de:kobv:5I7-opus4-82089

Postprints der Universität Potsdam

Mathematisch-Naturwissenschaftliche Reihe ; 200 



\title{
Metallomics
}

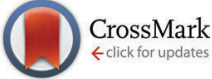

Cite this: Metallomics, 2015 7,1420

Received 26th June 2015 Accepted 27th July 2015

DOI: $10.1039 / c 5 m t 00171 d$

www.rsc.org/metallomics

\section{The blood-cerebrospinal fluid barrier - first evidence for an active transport of organic mercury compounds out of the brain}

\begin{abstract}
Hanna Lohren, ${ }^{a}$ Julia Bornhorst, ${ }^{a}$ Hans-Joachim Galla ${ }^{b}$ and Tanja Schwerdtle*a
Exposure to organic mercury compounds promotes primarily neurological effects. Although methylmercury is recognized as a potent neurotoxicant, its transfer into the central nervous system (CNS) is not fully evaluated. While methylmercury and thiomersal pass the blood-brain barrier, limited data are available regarding the second brain regulating interface, the blood-cerebrospinal fluid (CSF) barrier. This novel study was designed to investigate the effects of organic as well as inorganic mercury compounds on, and their transfer across, a porcine in vitro model of the blood-CSF barrier for the first time. The barrier system is significantly more sensitive towards organic $\mathrm{Hg}$ compounds as compared to inorganic compounds regarding the endpoints cytotoxicity and barrier integrity. Whereas there are low transfer rates from the blood side to the CSF side, our results strongly indicate an active transfer of the organic mercury compounds out of the CSF. These results are the first to demonstrate an efflux of organic mercury compounds regarding the CNS and provide a completely new approach in the understanding of mercury compounds specific transport.
\end{abstract}

\section{Introduction}

As a consequence of both, anthropogenic activities as well as natural processes, mercury $(\mathrm{Hg})$ is a ubiquitous contaminant and exists in various forms. Elemental mercury, inorganic mercury and organic mercury differ in their degree of toxicity, target organs and mechanisms of toxicity. ${ }^{1,2}$ Organic mercury compounds (such as methylmercury ( $\mathrm{MeHg}$ ) and thiomersal) exhibit toxic effects primarily in the central nervous system. ${ }^{3}$ Exposure to $\mathrm{MeHg}$ occurs predominantly via the consumption of contaminated fish. ${ }^{4} \mathrm{~A}$ further organic mercury compound of significant toxicological concern is thiomersal, which is used as a preservative in pharmaceutical products including vaccines ${ }^{5}$ and releases ethylmercury (EtHg) in aqueous solution. ${ }^{6}$

In vivo studies in the rat brain ${ }^{7}$ and in vitro studies in bovine capillary endothelial cells ${ }^{8}$ demonstrated that the $\mathrm{MeHg}$-cysteine conjugate (MeHg-S-Cys) enters the capillary endothelium of the blood-brain barrier via neutral amino acid transporters. Further studies in CHO-k1 cells identified MeHg-S-Cys as a substrate for the L-type large neutral amino acid transporter 1 (LAT1). ${ }^{9}$ Thus, it was assumed that $\mathrm{MeHg}$ crosses the blood-brain barrier by molecular mimicry of the essential amino acid methionine

\footnotetext{
${ }^{a}$ Department of Food Chemistry, Institute of Nutritional Science, University of Potsdam, Arthur-Scheunert-Allee 114 -116, 14558 Nuthetal, Germany. E-mail: Tanja.Schwerdtle@uni-potsdam.de

${ }^{b}$ Institute of Biochemistry, University of Muenster, Wilhelm-Klemm-Str. 2, 48149 Muenster, Germany
}

using LAT1 ${ }^{10}$ Recent in vitro based studies give evidence for a similar transfer mechanism by LAT1 for EtHg. ${ }^{11}$ Speciation analysis in murine brain tissue provides evidence that EtHg can reach the brain after intramuscular injection of $20 \mu \mathrm{g}$ thiomersal. ${ }^{12}$ The observed presence of inorganic mercury in the brain tissue is likely to be due to a dealkylation of the organic $\mathrm{Hg}$ compounds as well as an oxidation of elemental mercury in the brain. ${ }^{12,13}$

Besides the blood-brain barrier, the blood-cerebrospinal fluid (CSF) barrier represents a further interface for the access of mercury compounds into the brain. It is built up by epithelial cells of the choroid plexus, which separates the blood from the CSF. So far the transfer of the respective organic mercury compounds across this physiological barrier has not been characterized, albeit some evidence exists that cells of the choroid plexus accumulate mercury. ${ }^{14} \mathrm{~A} \mathrm{Hg}$ accumulation in the choroid plexus tissue of $\mathrm{MeHg}$ treated rats as well as a mercury deposition in epithelial choroid plexus cells of a Minamata disease patient 26 years after exposure is described. ${ }^{15,16}$ Additionally, Nakamura et al. concluded, that in rats a repeated oral administration of $\mathrm{MeHgCl}\left(10 \mathrm{mg} \mathrm{kg}^{-1}\right.$ b.w.) on five consecutive days impairs the function of the blood-CSF barrier, followed by a leakage of albumin-bound $\mathrm{MeHg}$ from plasma into CSF and neurotoxic effects. ${ }^{17}$

The present study aims to elucidate the role of the blood-CSF barrier in the toxicokinetics of inorganic and organic $\mathrm{Hg}$ compounds for the first time. It compares the effects of the organic mercury compounds $\mathrm{MeHgCl}$ and thiomersal and the inorganic mercury compound mercury chloride $\left(\mathrm{HgCl}_{2}\right)$ on as well as their transfer in both directions across a primary in vitro blood-CSF barrier model. 


\section{Experimental}

\section{Primary in vitro blood-CSF barrier}

Primary porcine choroid plexus epithelial cells (PCPECs) were isolated from choroid plexus tissue derived from freshly slaughtered pigs as previously described. ${ }^{18,19}$ The PCPECs were seeded on microporous Transwell ${ }^{\circledR}$ filter inserts $\left(1.12 \mathrm{~cm}^{2}\right.$ growth area,

Table 1 ICP-MS parameters

\begin{tabular}{ll}
\hline Forward power & $1550 \mathrm{~W}$ \\
Cool gas flow & $15 \mathrm{~L} \mathrm{~min}^{-1}$ \\
Auxiliary gas flow & $0.9 \mathrm{~L} \mathrm{~min}^{-1}$ \\
Nebulizer gas flow & $1 \mathrm{~L} \mathrm{~min}^{-1}$ \\
Nebulizer type & $\mathrm{MicroMist}^{200}$ \\
Isotopes & ${ }^{200} \mathrm{Hg}{ }^{202} \mathrm{Hg}$ \\
LOD $^{a}$ & $0.8 \mathrm{ng} \mathrm{L}^{-1}$ \\
LOQ $^{a}$ & $2.9 \mathrm{ng} \mathrm{L}^{-1}$ \\
${ }^{a}$ DIN 32645. &
\end{tabular}

$0.4 \mu \mathrm{M}$ pore size; Corning, Wiesbaden, Germany) and cultivated as described before. ${ }^{18}$

\section{Mercury compounds}

Stock solutions of $\mathrm{MeHgCl}$ ( $>99.9 \%$ purity, Sigma Aldrich, Deisenhofen, Germany), thiomersal ( $>97 \%$ purity, Sigma Aldrich) and $\mathrm{HgCl}_{2}$ (>99.999\% purity, Sigma Aldrich) were prepared in sterile distilled water shortly before each experiment.

\section{Cytotoxicity testing}

Cytotoxic effects of the mercury compounds were evaluated after $72 \mathrm{~h}$ incubation by quantifying the lysosomal integrity using the neutral red uptake assay. PCPECs were cultivated in 96 well culture plates and were incubated with the respective mercury compounds on day in vitro (DIV) 14 . The cytotoxicity assay was carried out as previously described. ${ }^{18}$
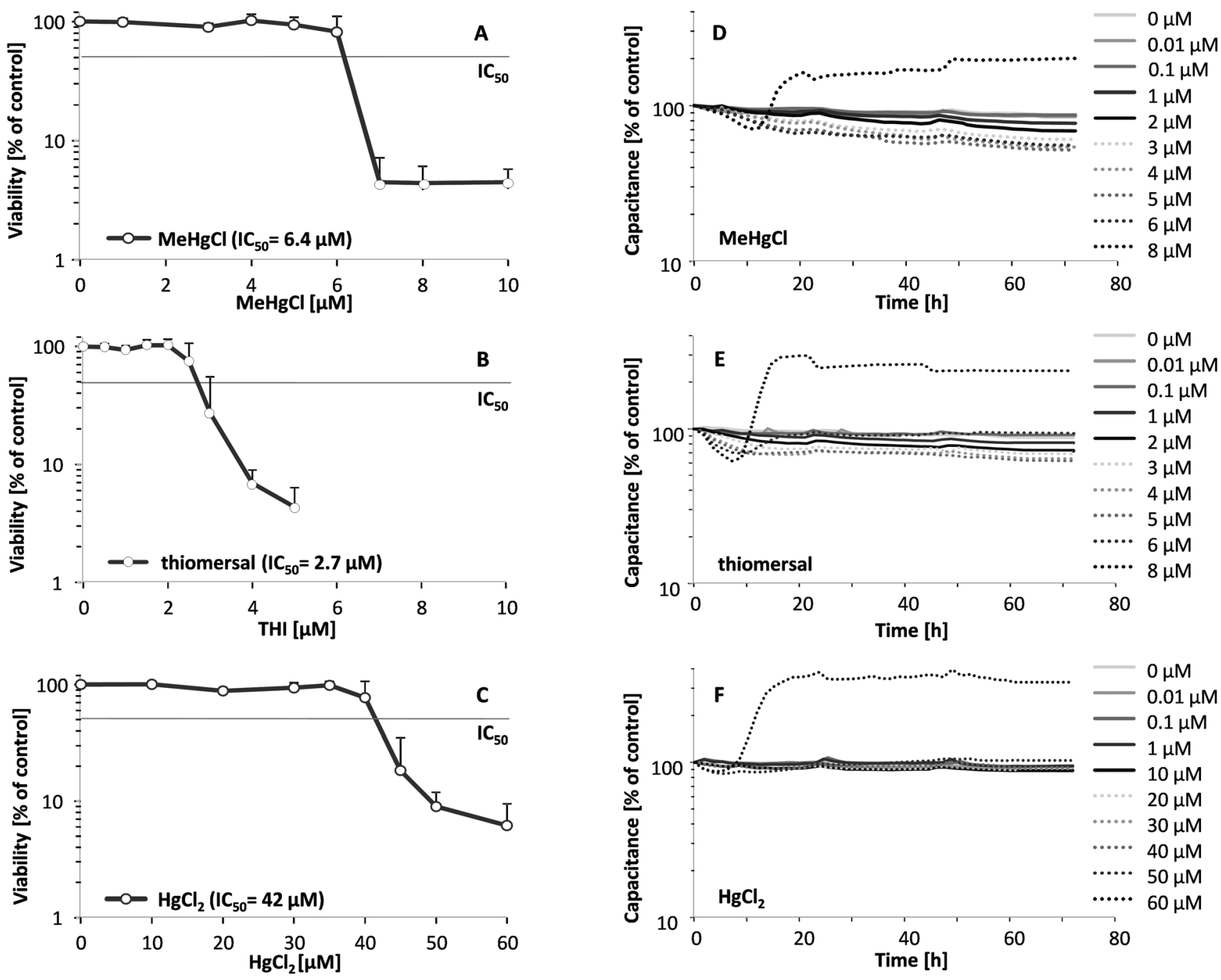

Fig. 1 Cytotoxicity of $\mathrm{MeHgCl}(\mathrm{A})$, thiomersal (B) and $\mathrm{HgCl}_{2}$ (C) in PCPECs after $72 \mathrm{~h}$ incubation. Cytotoxicity was determined by a decrease of lysosomal integrity measured by neutral red uptake. Shown are mean values of at least 3 independent determinations with 6 replicates each $+\mathrm{SD}$. Effect of $\mathrm{MeHgCl}$ (D), thiomersal (E) and $\mathrm{HgCl}_{2}$ (F) on the electrical capacitance after basolateral incubation for $72 \mathrm{~h}$. Shown are mean values of at least 3 independent cell preparations with at least 2 independent determinations each with SD $< \pm 10 \%$ (not shown). 


\section{Cellular bioavailability}

Total cellular mercury content was quantified $72 \mathrm{~h}$ after incubation with the respective compounds by inductively coupled plasma mass spectrometry (ICP-MS; Agilent 8800 ICP-QQQ, Agilent Technologies Deutschland $\mathrm{GmbH}$, Böblingen, Germany). PCPECs were cultivated in 24 well culture plates under the same conditions as the cells seeded on Transwell ${ }^{\circledR}$ filter inserts. After treatment with the respective mercury compounds, PCPECs were washed twice with PBS and incubated with $120 \mu \mathrm{L}$ RIPA-buffer (0.01 M Tris, pH 7.6, 0.15 M NaCl, 0.001 M EDTA, 1\% sodium desoxycholate, 0.1\% (all Sigma Aldrich)) for $15 \mathrm{~min}$ on ice. After scrapping off and sonication, the cell suspension was centrifuged at $10000 \times g$ for $20 \mathrm{~min}$ at $4{ }^{\circ} \mathrm{C}$. The Bradford assay was used to elucidate the cellular protein level and ICP-MS analysis was carried out for the quantification of the total mercury concentration of the supernatant.

Evaluation of the barrier integrity and the capacitance as well as the transfer across the in vitro model of the blood-CSF barrier

After isolation, the PCPECs were seeded on microporous Transwell $^{\circledR}$ filter inserts and cultivated as described before. ${ }^{18}$

After 8 days of proliferation (DIV 1-9) and 6 days of differentiation under serum free conditions (DIV 9-14) the cells built up a tight barrier and obtained functions mimicking the in vivo situation. ${ }^{20}$ In correspondence with the secretion of cerebrospinal fluid in vivo, fully differentiated cells transfer cell culture medium from the basolateral (blood facing) to the apical (CSF facing) compartment. Furthermore, phenol red is transported out of the apical to the basolateral compartment. The clearance of phenol red against a concentration gradient is indicative for fully developed transfer properties and the tightness of the barrier. ${ }^{18,20}$

On DIV 14 the respective mercury compounds were applied in a concentration range of $0.01-8 \mu \mathrm{M}$ ( $\mathrm{MeHgCl}$ and thiomersal) or 0.01-60 $\mu \mathrm{M}\left(\mathrm{HgCl}_{2}\right)$ either on the basolateral or on the apical or on both sides simultaneously by replacing $10 \%$ of the culture medium with fresh mercury compounds containing medium in the respective compartment. During $72 \mathrm{~h}$ of incubation, the transepithelial electrical resistance (TEER) was monitored as parameter for the integrity of the barrier by the cellZscope ${ }^{\circledR}$ (nanoAnalytics, Münster, Germany). Furthermore, the capacitance, which is related to the plasma membrane surface area, was recorded continuously (cellzscope ${ }^{\circledR}$; nanoAnalytics, Münster, Germany). For each experiment minimum TEER values of $600 \Omega \times \mathrm{cm}^{2}$ and a capacitance of $3.0 \mu \mathrm{F} \mathrm{cm} \mathrm{cm}^{-2}$ as indicative values for tight barrier properties were provided. Besides the TEER the absorption of phenol red was determined as parameter for the tightness of the barrier (558 nm, NanoDrop 1000, PEQLAB Biotechnologie GmbH, Erlangen, Germany).

For transfer studies, aliquots of both compartments were taken after $0,6,24,48$ and $72 \mathrm{~h}$ in case of incubation on one side and after $0,1.5,3,6,24,48$ and $72 \mathrm{~h}$ in case of application on both sides simultaneously. The total mercury amount in these aliquots was quantified by ICP-MS. Mercury transfer was calculated as percent (\%) in relation to the total mercury content in both compartments.

In a further experiment transporter specific inhibitors were used to identify possible transport mechanisms. Fumitremorgin
C ( $>98 \%$ purity) was used to inhibit the ATP binding cassette (ABC)-transporter G2 (ABCG2), PSC 833 (valspodar, >98\% purity) to inhibit P-glycoprotein (P-gp/ABCB1) and indomethacin (>99\% purity, all Sigma Aldrich) to inhibit organic anion transporter 2 (OAT2) and/or multidrug resistance associated protein (MRP), respectively. ${ }^{21-23}$ The stock solutions of the respective inhibitors were prepared in dimethyl sulfoxide (DMSO, Roth, Karlsruhe, Germany) and applied in the apical as well as in the basolateral compartment simultaneously with a final inhibitor concentration of $10 \mu \mathrm{M} 1 \mathrm{~h}$ before treatment with the mercury compounds on both sides $(1 \mu \mathrm{M})$. The DMSO concentration did not exceed a concentration of $1 \%$ in the wells.

\section{Immunocytochemical staining}

The immunocytochemical staining of occludin was performed in PCPECs grown as a monolayer on Transwell ${ }^{\circledR}$ filters as described before. ${ }^{18}$ Briefly, $1 \mu \mathrm{g} \mathrm{mL}{ }^{-1}$ mouse anti occludin (Zytomed, Berlin, Germany) as first antibody and alexa fluor ${ }^{\circledR} 546$ goat anti-mouse (Invitrogen, Paisley, UK) as secondary antibody were incubated in $0.5 \%$ bovine serum albumin solution (BSA, Roth) at $37{ }^{\circ} \mathrm{C}$ for $30 \mathrm{~min}$. Additionally, cell nuclei were stained with $10 \mu \mathrm{g} \mathrm{mL}$ Hoechst 33258 (Bisbenzimide, Sigma Aldrich) for $0.5 \mathrm{~min}$ before the filters were mounted in aqua poly/mount (Polysciences, Washington, USA). The fluorescence microscope Axio ImagerM2 (Zeiss, Oberkochen, Germany) with the software Axiovision 4.5 (Zeiss, Göttingen, Germany) was used.

\section{ICP-MS analysis}

Total mercury in samples taken from the transfer studies and cellular bioavailability studies was measured by ICP-MS using external calibration (1-150 $\mathrm{ng} \mathrm{\textrm {L } ^ { - 1 }}$; mercury standard for ICP, TraceCERT $^{\circledR}$, Fluka, Deisenhofen, Germany). $10 \mathrm{ng} \mathrm{\textrm {L } ^ { - 1 }}$ rhodium (10 Merck KGaA, Darmstadt, Germany) were used as internal standard to observe and overcome short- and long-term drift effects and to compensate possible matrix related effects. The calibration was prepared and the samples were diluted in a solution of $5 \%$ $\mathrm{HNO}_{3}+5 \% \mathrm{HCl}(\mathrm{v} / \mathrm{v}$, both suprapur, Merck KGaA). This solution contributes to the stability of mercury in this concentration range. ${ }^{24}$

Table 2 Cellular bioavailability of $\mathrm{MeHgCl}$, thiomersal and $\mathrm{HgCl}_{2}$ in $\mathrm{PCPECs}$ after $72 \mathrm{~h}$ incubation. Data represent mean values of at least 2 independent cell preparations with 2 independent determinations each \pm SD

\begin{tabular}{lcl}
\hline & Concentration $[\mu \mathrm{M}]$ & $\begin{array}{l}\text { Cellular Hg } \\
{\left[\mu \mathrm{Hg} \mathrm{mg}^{-1} \text { protein }\right]}\end{array}$ \\
\hline Control & 0 & $0.001 \pm 0.001$ \\
$\mathrm{MeHgCl}$ & 0.1 & $0.064 \pm 0.030$ \\
& 1 & $0.529 \pm 0.173$ \\
& 3 & $2.484 \pm 0.886$ \\
Thiomersal & 0.1 & $0.094 \pm 0.040$ \\
& 1 & $0.437 \pm 0.165$ \\
& 3 & $1.640 \pm 0.378$ \\
$\mathrm{HgCl}_{2}$ & 3 & \\
& 25 & $0.086 \pm 0.027$ \\
& 50 & $0.393 \pm 0.182$ \\
& & $0.321 \pm 0.222$
\end{tabular}


The addition of a gold solution ( $1 \mathrm{mg} \mathrm{L}^{-1}$, Merck $\left.\mathrm{KGaA}\right)$ to $5 \%$ $\mathrm{HNO}_{3}+5 \% \mathrm{HCl}$ decreases memory effects. ${ }^{25}$ Further ICP-MS conditions are listed in Table 1.

\section{Results}

\section{Cellular toxicity and bioavailability}

Cellular toxicity of the respective mercury compounds were monitored in confluent PCPECs by assessing cell viability via the endpoint lysosomal integrity as well as during the transfer studies by the measurement of capacitance, which is directly proportional to the plasma membrane surface area. Thiomersal $\left(\mathrm{IC}_{50} 2.7 \mu \mathrm{M}\right)$ and $\mathrm{MeHgCl}\left(\mathrm{IC}_{50} 6.4 \mu \mathrm{M}\right)$ exerted stronger cytotoxicity compared to $\mathrm{HgCl}_{2}\left(\mathrm{IC}_{50} 42 \mu \mathrm{M}\right)$ (Fig. 1A-C). The continuous monitoring of the electrical capacitance after basolateral (blood side) incubation within the in vitro model of the blood-CSF barrier confirmed the higher cellular toxicity of the organic $\mathrm{Hg}$ compounds (Fig. 1D-F). The results of the capacitance measurement after apical (CSF side) incubation
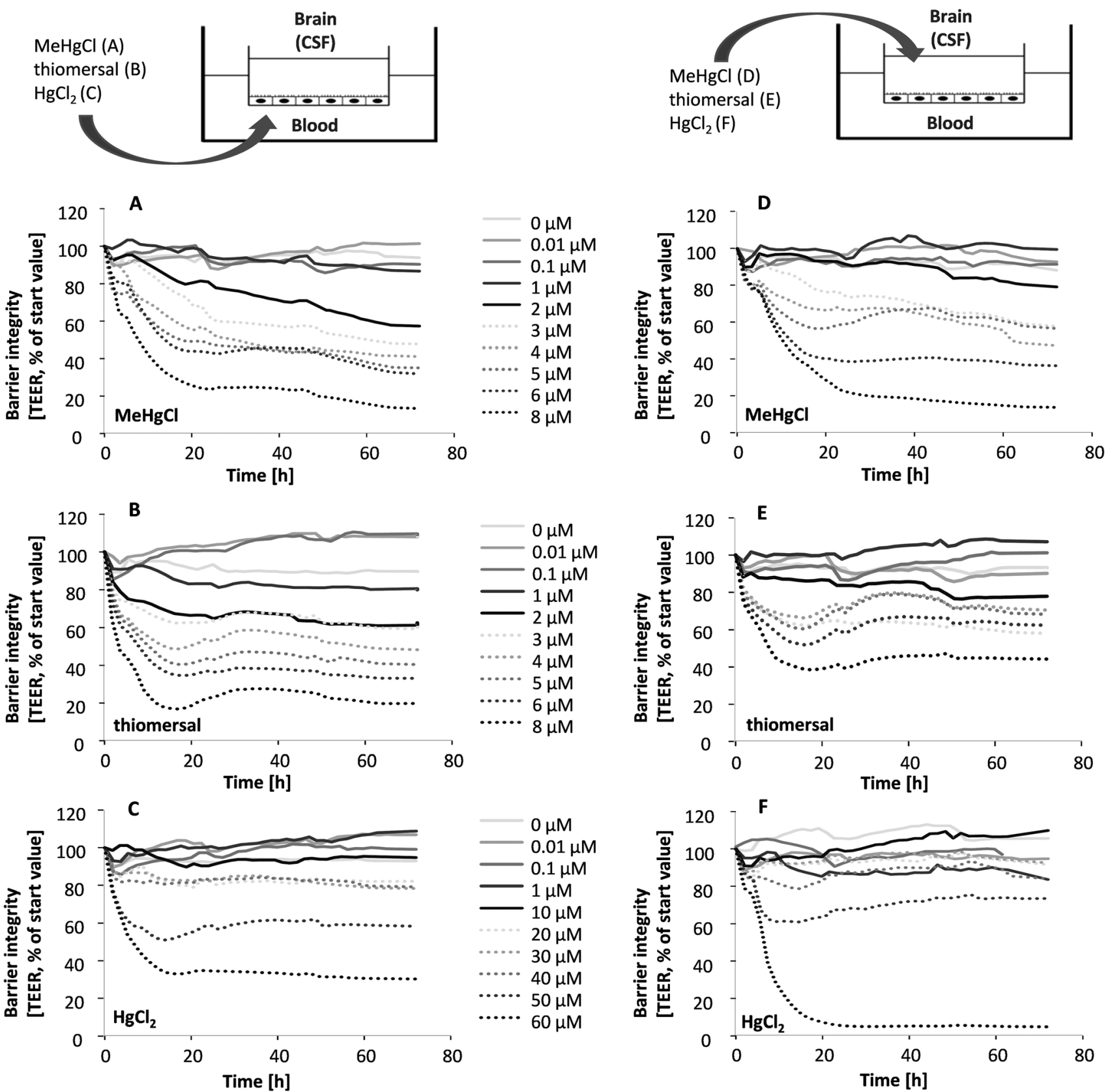

Fig. 2 Effect on the barrier integrity of the PCPEC monolayer after incubation with $\mathrm{MeHgCl}$, thiomersal and $\mathrm{HgCl}_{2}$ in the basolateral compartment (blood side, A-C) and in the apical compartment (CSF side, D-F) for $72 \mathrm{~h}$. Barrier integrity was determined by online measurement of the TEER. Shown are mean values of at least 3 independent cell preparations with at least 2 independent determinations each. 
are comparable (data not shown). With increasing incubation concentrations, the capacitance decreased due to alterations of the epithelial cell surface (e.g. reduction of microvilli). At the highest concentration $(8 \mu \mathrm{M}$ for the organic compounds and $60 \mu \mathrm{M}$ in the case of $\mathrm{HgCl}_{2}$ ) the electrical capacitance shows an increase indicating an enlarged cell volume or detached cells.

The higher cellular total mercury concentrations after incubation with the organic mercury compounds (Table 2) argue for a higher cellular bioavailability of $\mathrm{MeHgCl}$ and thiomersal than for $\mathrm{HgCl}_{2}$ and correlate well with the observed higher cellular toxicity of the organic $\mathrm{Hg}$ compounds.

\section{Evaluation of the barrier integrity and function}

The in vitro model of the blood-CSF barrier is built up by fully differentiated PCPECs cultivated on Transwell ${ }^{\circledR}$ filter inserts between two fluid compartments filled with cell culture medium. The upper apical compartment represents the CSF side in vivo whereas the lower basolateral compartment mimics the blood side. The integrity of the barrier is a function of paracellular

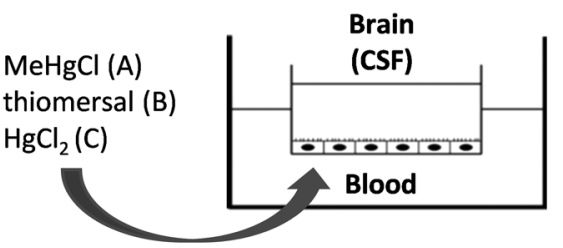

更

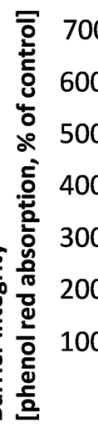

\section{A}

$$
\rightarrow-\text { CSF side }
$$

- - blood side

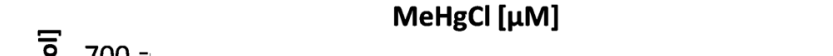

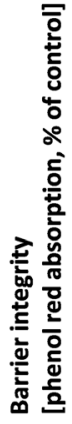

B

600 - -0 CSF side

$500-$

$400-\quad 0-$ blood side

$300-$

$200-$

100

0

$0 \quad 2$

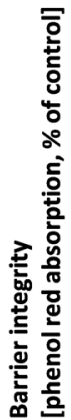

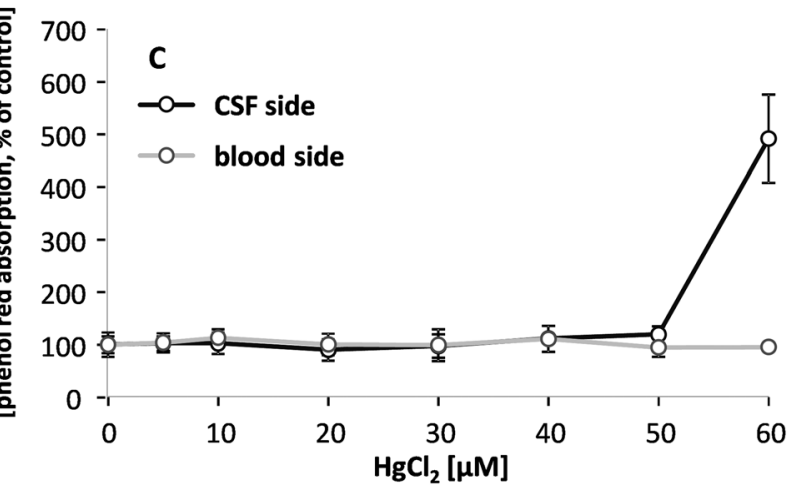

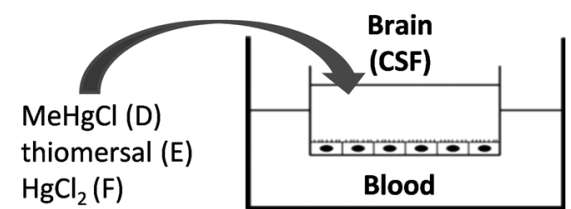
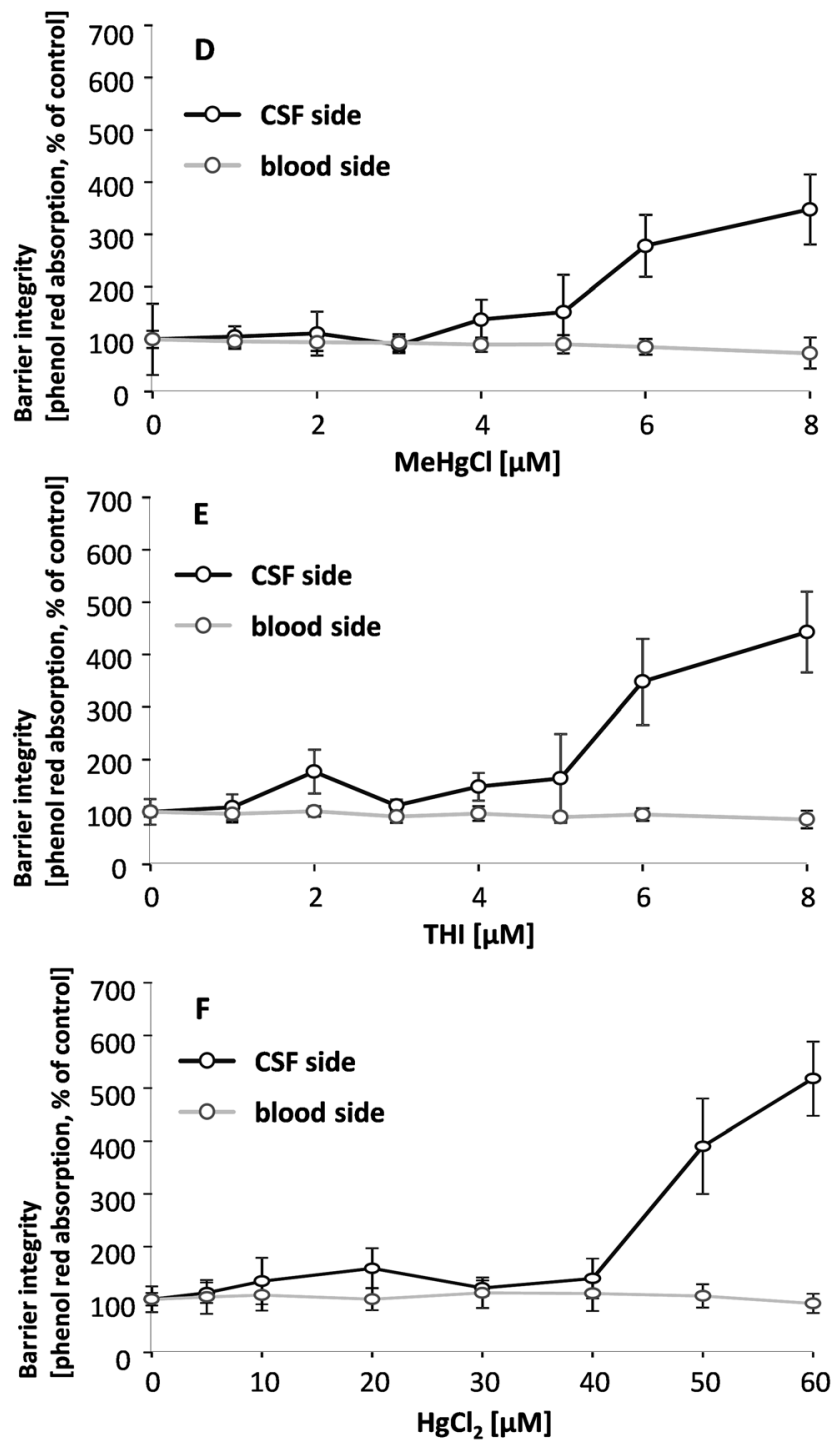

Fig. 3 Phenol red concentration determined by measurement of the absorption ( $558 \mathrm{~nm}$ ) after incubation with $\mathrm{MeHgCl}$ thiomersal and $\mathrm{HgCl} 2$ in the basolateral compartment (blood side, $\mathrm{A}-\mathrm{C}$ ) and in the apical compartment (CSF side, D-F) for $72 \mathrm{~h}$. Shown are mean values of at least 3 independent cell preparations with at least 2 independent determinations each \pm SD. 
permeability and was assessed in the present study by a continuous measurement of the TEER during the entire transfer experiments. The effect of $\mathrm{MeHgCl}$ on barrier integrity was comparable after basolateral or apical application, whereas thiomersal affected the tightness of the barrier more pronounced after basolateral incubation and $\mathrm{HgCl}_{2}$ after apical incubation (Fig. 2A-F).

Besides the continuous monitoring of the TEER, the clearly visible reduction of the fluid secretion (not quantified) and the phenol red concentration (Fig. 3A-F) in the apical compartment were measured as parameters indicating changes in barrier properties. The phenol red data confirm the TEER measurements. After apical incubation or basolateral incubation, barrier integrity as well as barrier function is massively disturbed in the presence of $60 \mu \mathrm{M} \mathrm{HgCl}_{2}, 8 \mu \mathrm{M} \mathrm{MeHgCl}$ or $8 \mu \mathrm{M}$ thiomersal. An incubation with up to $1 \mu \mathrm{M}$ of the respective compounds in either the apical or the basolateral compartment did neither affect barrier integrity nor barrier function. $1 \mu \mathrm{M}$ was therefore chosen as the maximum concentration for the transfer experiments.

Since $\mathrm{MeHgCl}$ and thiomersal affected barrier integrity at concentrations below the respective $\mathrm{IC}_{50}$ viability values, occludin immunostaining was carried out to study the assembly and function of tight junctions, which mainly control the paracellular pathway. ${ }^{26}$ In untreated cells, occludin staining appeared in clear lines, without any fuzzy appearance, and cell borders were mostly straight and not serrated (Fig. 4A and D); similar pictures were obtained in case of a $48 \mathrm{~h}$ incubation with $1 \mu \mathrm{M}$ thiomersal or MeHgCl (Fig. 4B and E). In contrast, barriers treated for $48 \mathrm{~h}$ with $3 \mu \mathrm{M}$ thiomersal or $5 \mu \mathrm{M} \mathrm{MeHgCl}$ showed more serrated
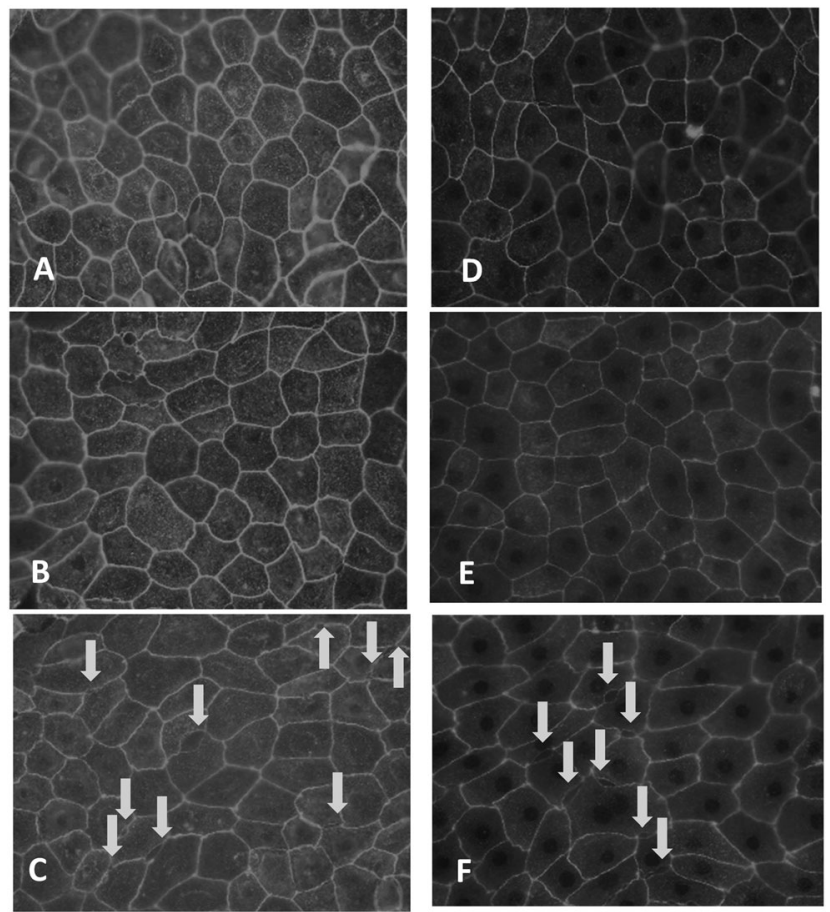

Fig. 4 Immunocytochemical staining of occludin in non-treated barriers ( $A$ and $D$, TEER $=856,1003 \Omega \times \mathrm{cm}^{2}$ ) and after incubation with $1 \mu \mathrm{M}$ $\mathrm{MeHgCl}\left(\mathrm{B}, \mathrm{TEER}=927 \Omega \times \mathrm{cm}^{2}\right), 5 \mu \mathrm{M} \mathrm{MeHgCl}\left(\mathrm{C}, \mathrm{TEER}=1023 \Omega \times \mathrm{cm}^{2}\right)$, $1 \mu \mathrm{M}$ thiomersal $\left(\mathrm{E}, \mathrm{TEER}=901 \Omega \times \mathrm{cm}^{2}\right)$ and $3 \mu \mathrm{M}$ thiomersal $(\mathrm{F}, \mathrm{TEER}=$ $976 \Omega \times \mathrm{cm}^{2}$ ) for $48 \mathrm{~h}$. Arrows indicate perforated cell borders. and perforated cell borders, indicating that tight junctions were not fully closed anymore (Fig. 4C and F).

\section{Transfer across the in vitro model of the blood-CSF barrier}

Transfer studies were performed in a low concentration range of the mercury compounds $(0.01,0.1$ and $1 \mu \mathrm{M})$ on the one hand to ensure an intact barrier and on the other hand to be as close to the in vivo situation as possible. Population groups with high fish and seafood consumption exhibit total $\mathrm{Hg}$ blood concentrations of $0.6-30 \mu \mathrm{g} \mathrm{L}^{-1}(0.03-0.15 \mu \mathrm{M}) .{ }^{27}$ An in vivo study comparing $\mathrm{Hg}$ blood levels two days after oral $\mathrm{MeHg}$ intake (20 $\mu \mathrm{g} \mathrm{kg}^{-1}$ as $\mathrm{MeHg}$ hydroxide) and intramuscular thiomersal injection $\left(20 \mu \mathrm{g} \mathrm{kg}^{-1}\right)$ in infant monkeys demonstrated total blood $\mathrm{Hg}$ concentrations of 8-18 $\mathrm{ng} \mathrm{mL} \mathrm{mL}^{-1}(0.04-0.09 \mu \mathrm{M})$ and of 6-14 ng L ${ }^{-1}(0.03-0.07 \mu \mathrm{M})$, respectively. ${ }^{13}$ The application in the blood facing compartment lead to similar transfer rates for all mercury compounds (Fig. 5A-C). Thus, after 6 to $72 \mathrm{~h}$ of incubation a maximum of $25 \%$ of the total mercury content was quantified in the CSF-facing compartment.

In a second set of experiments, the transfer from the CSF side to the blood side (efflux) was investigated (Fig. 5D-F). After $6 \mathrm{~h}$ of $\mathrm{MeHgCl}$ or thiomersal, exposure about $70-100 \%$ was concentrated on the blood side compartment. This is in strong contrast to the inorganic mercury compound. Thus, after basolateral $\mathrm{HgCl}_{2}$ incubation, mercury did not accumulate on the blood side, with a maximum transfer rate of $25 \%$. The detailed presentation of the mercury levels measured in both compartments after apical incubation with $1 \mu \mathrm{M}$ of $\mathrm{MeHgCl}$, thiomersal or $\mathrm{HgCl}_{2}$, additionally illustrates the efflux of the organic mercury compounds (Fig. 6A-F). In case of barrier disruption ( $8 \mu \mathrm{M} \mathrm{MeHgCl}$ or thiomersal, $60 \mu \mathrm{M} \mathrm{HgCl}_{2}$ ) the $\mathrm{Hg}$ compounds are easily transferred towards the respective target compartments until a concentration equation of mercury was achieved in both compartments (Fig. 7A-F).

In addition to the application of the compounds in one compartment, $1 \mu \mathrm{M}$ of $\mathrm{MeHgCl}$, thiomersal and $\mathrm{HgCl}_{2}$ were incubated on both sides simultaneously (Fig. 8A-C). The rapid accumulation in the blood-facing compartment following $\mathrm{MeHgCl}$ or thiomersal incubation in parallel on both sides provides strong evidence for an active transport efflux mechanism for the organic mercury compounds. After parallel incubation of $\mathrm{HgCl}_{2}$ in both compartments, mercury did accumulate neither on the blood nor on the brain-facing compartment.

In a further experiment fumitremorgin $\mathrm{C}$ as inhibitor of ABCG2, PSC 833 as inhibitor of the P-gp and indomethacin as substrate for OAT2 and the MRP family were incubated before treatment with the respective mercury compounds, to facilitate the identification of specific transporter for the organic mercury compounds. Transfer properties were not significantly different as compared to simultaneous incubation of the respective mercury compounds on both sides without inhibitors (data not shown).

\section{Discussion}

Transfer of organic mercury compounds across the bloodbrain barrier is well discussed in literature and seems to be 

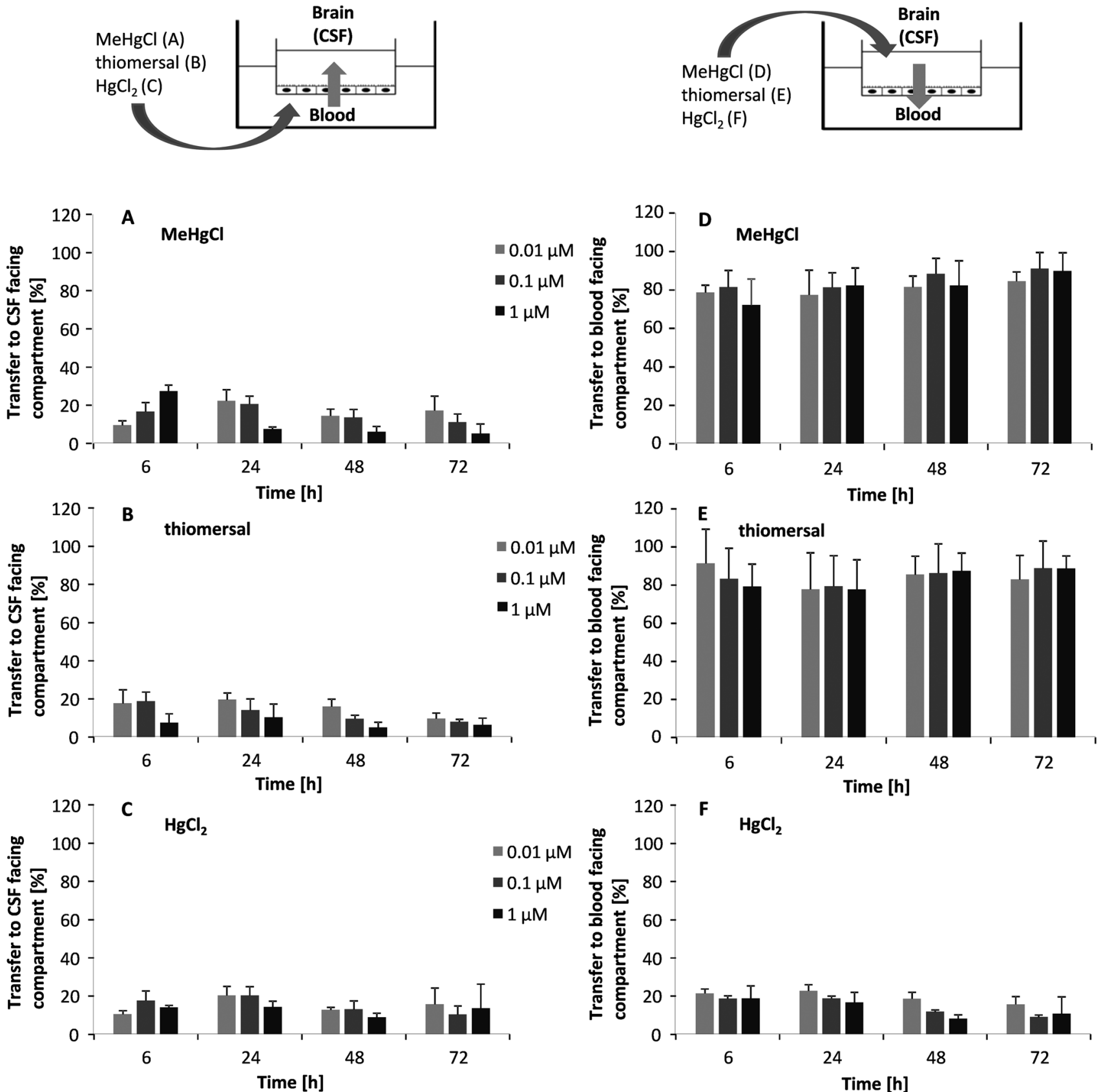

Fig. $5 \mathrm{Hg}$ transfer after incubation with $\mathrm{MeHgCl}$, thiomersal and $\mathrm{HgCl}_{2}$ in the basolateral compartment (blood side, A-C) and in the apical compartment (CSF side, D-F) for $72 \mathrm{~h}$. Data are expressed as \% of the whole mercury amount measured in both compartments of each well in the acceptor compartment. The mercury content was quantified by ICP-MS. Shown are mean values of at least 3 independent cell preparations with 3 independent determinations each + SD.

mediated by molecular mimicry. ${ }^{11,14,28}$ Until now, the involvement of the blood-CSF barrier in transfer of $\mathrm{Hg}$ compounds remains largely unexplored to our knowledge. In the present study we applied a well characterized cell culture model of the blood-CSF barrier derived from PCPECs ${ }^{19}$ to investigate effects on and transfer across this important barrier in both directions (influx and efflux) after exposure to organic ( $\mathrm{MeHgCl}$ and thiomersal) and inorganic $\left(\mathrm{HgCl}_{2}\right)$ mercury compounds for the first time.

Within this study, we could show that the cellular bioavailability in PCPECs is higher following $72 \mathrm{~h}$ incubation with organic $\mathrm{MeHgCl}$ or thiomersal as compared to $72 \mathrm{~h}$ incubation with inorganic $\mathrm{HgCl}_{2}$. These higher mercury bioavailabilities after incubation with the organic mercury compounds correlate well with their stronger cytotoxic effects.

The results of the barrier integrity determined by continuous monitoring of the TEER values indicate that the compoundinduced barrier disruption with TEER values below $40 \%$ of the start value is correlating with their cytotoxicity. $\mathrm{MeHgCl}$ and thiomersal showed effects on the barrier integrity at concentrations below the respective $\mathrm{IC}_{50}$ viability values, which are visualized 

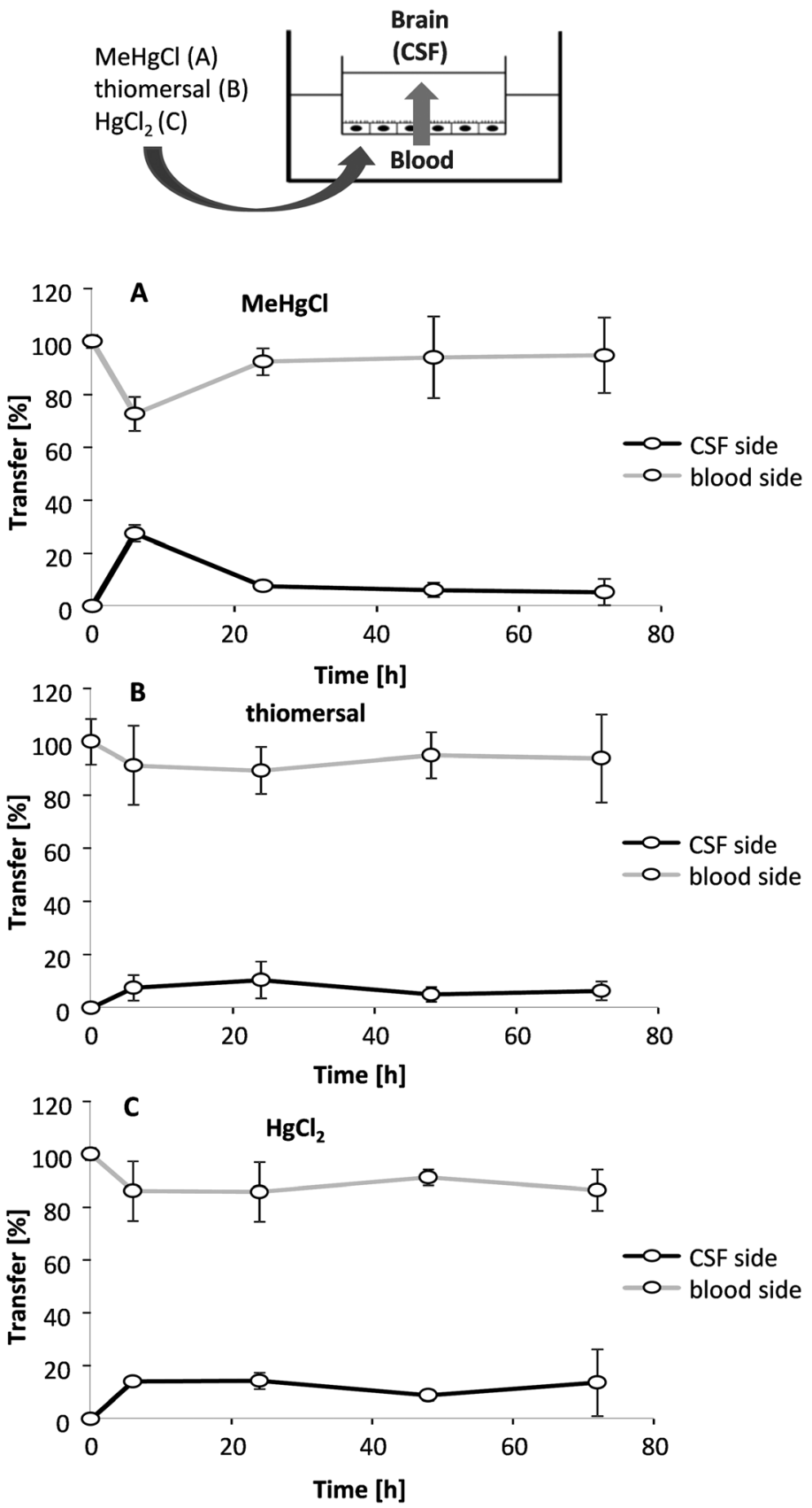
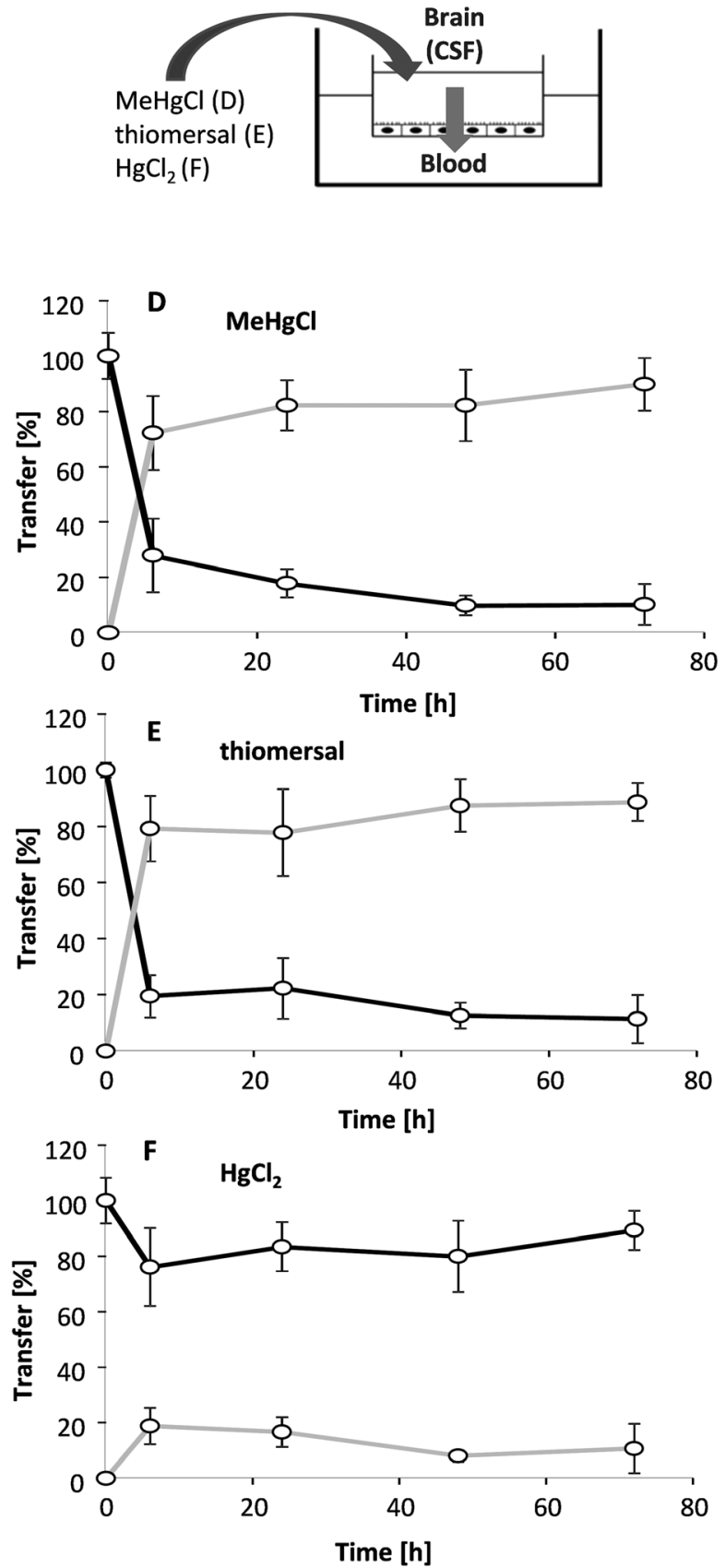

Fig. $6 \mathrm{Hg}$ transfer after incubation with $\mathrm{MeHgCl}$, thiomersal and $\mathrm{HgCl}_{2}(1 \mu \mathrm{M})$ in the basolateral compartment (blood side, A-C) and in the apical compartment (CSF side, D-F) for $72 \mathrm{~h}$. Data are expressed as \% of the whole mercury amount measured in both compartments. The mercury content was quantified by ICP-MS. Shown are mean values of at least 3 independent cell preparations with 3 independent determinations each \pm SD.

by occludin immunostaining. When the integrity of the barrier was lost, the organic mercury compounds were able to enter the brainfacing compartment and a concentration equation was achieved in both compartments. This is in accordance to the data reported by Nakamura et al., in which repeated high oral dose application of $\mathrm{MeHgCl}$ in rats caused blood-CSF barrier disruption, resulting in high mercury concentrations in the CSF of the rats. ${ }^{17}$

In contrast to the postulated transport of organic mercurycysteine conjugates across the blood-brain barrier towards the brain side via $\mathrm{LAT}^{16}$ our results do not indicate a comparable transfer across the blood-CSF barrier. Neither the organic nor the inorganic mercury compounds seem to be substantially transferred towards the brain-facing compartment following blood side incubation in the in vitro model of the blood-CSF barrier. In accordance with the low transfer of the organic mercury compounds towards the brain-facing compartment is that in rat choroid plexus immunostaining demonstrated LAT1 localization at the basolateral but not the apical surface. ${ }^{29,30}$

Since studies regarding an efflux of mercury compounds out of the brain into the blood do not exist in literature, $\mathrm{MeHgCl}$, 

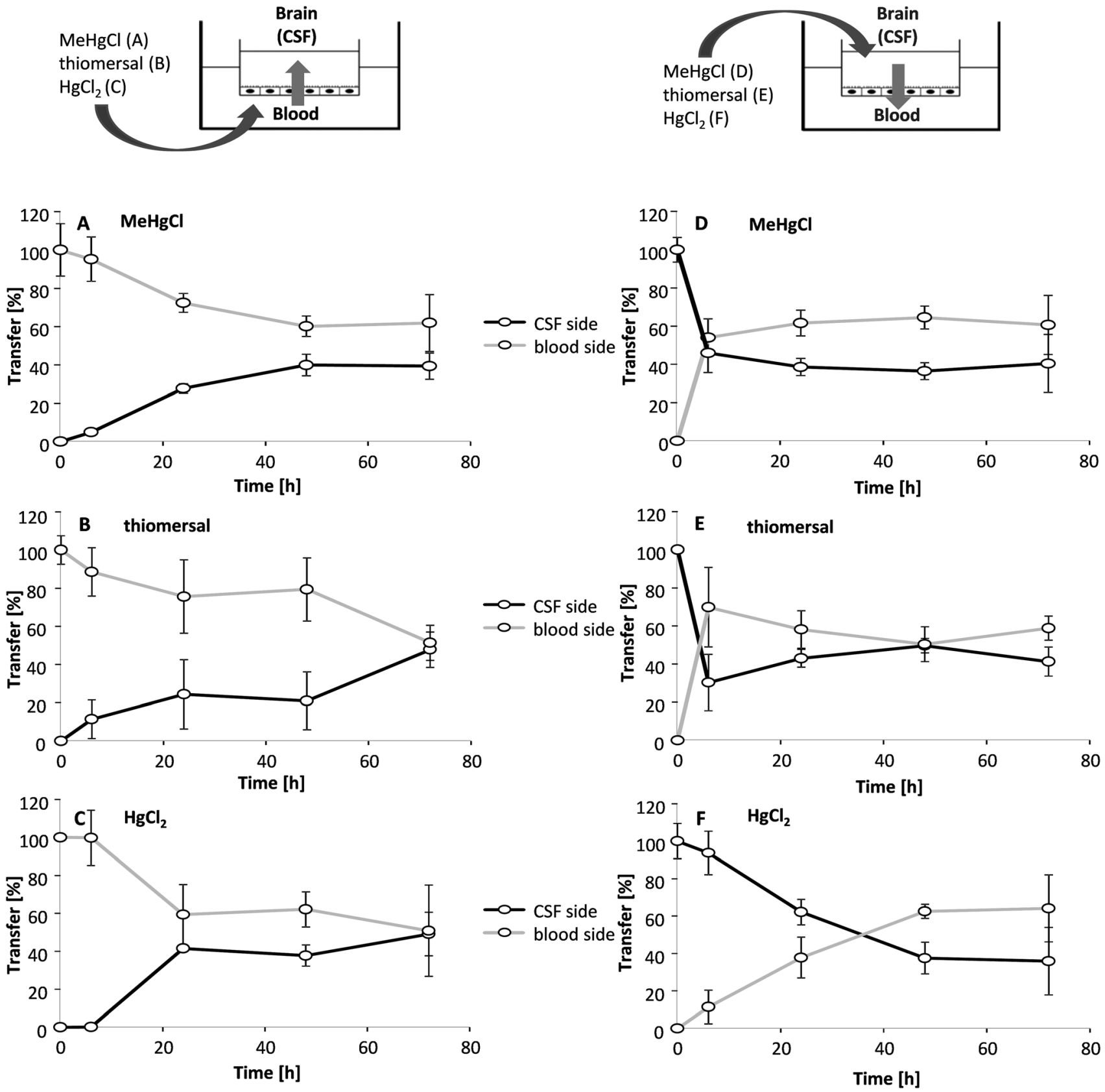

Fig. $7 \mathrm{Hg}$ transfer after incubation with $\mathrm{MeHgCl}$, thiomersal $(8 \mu \mathrm{M})$ and $\mathrm{HgCl}_{2}(60 \mu \mathrm{M})$ in the basolateral compartment (blood side, A-C) and in the apical compartment (CSF side, D-F) for $72 \mathrm{~h}$. Data are expressed as \% of the whole mercury amount measured in both compartments. The mercury content was quantified by ICP-MS. Shown are mean values of at least 3 independent cell preparations with 3 independent determinations each \pm SD.

thiomersal and $\mathrm{HgCl}_{2}$ were applied in the apical, CSF-facing chamber. Surprisingly, these studies demonstrate a fast and effective transfer against the concentration gradient from the CSF side to the blood side strongly indicating an active transport mechanism. The transfer rate of $\mathrm{HgCl}_{2}$ is comparable to the transfer after blood side exposure and does not show any accumulation neither on the blood side nor on the CSF side. These results are in accordance to the simultaneous incubation with the compounds on both sides where the transport against the concentration gradient is clearly observable. The rapid transport towards and the accumulation on the blood side might point towards a possible role of the blood-CSF barrier as a detoxification mechanism in organic mercury mediated neurotoxicity. A major target of mercury mediated neurotoxicity is the developing brain..$^{31}$ Exposure to $\mathrm{MeHg}$ during early fetal development can cause neurodevelopmental injury at doses much lower than those affecting adult brain function. ${ }^{32,33}$ Due to the early differentiation and growth of the choroid plexus compared to the subsequent vascularization in the developing brain, it has been suggested that in early development the main portal of molecular transfer from blood into the brain is via the choroid plexus and CSF rather than via the sparsely distributed 

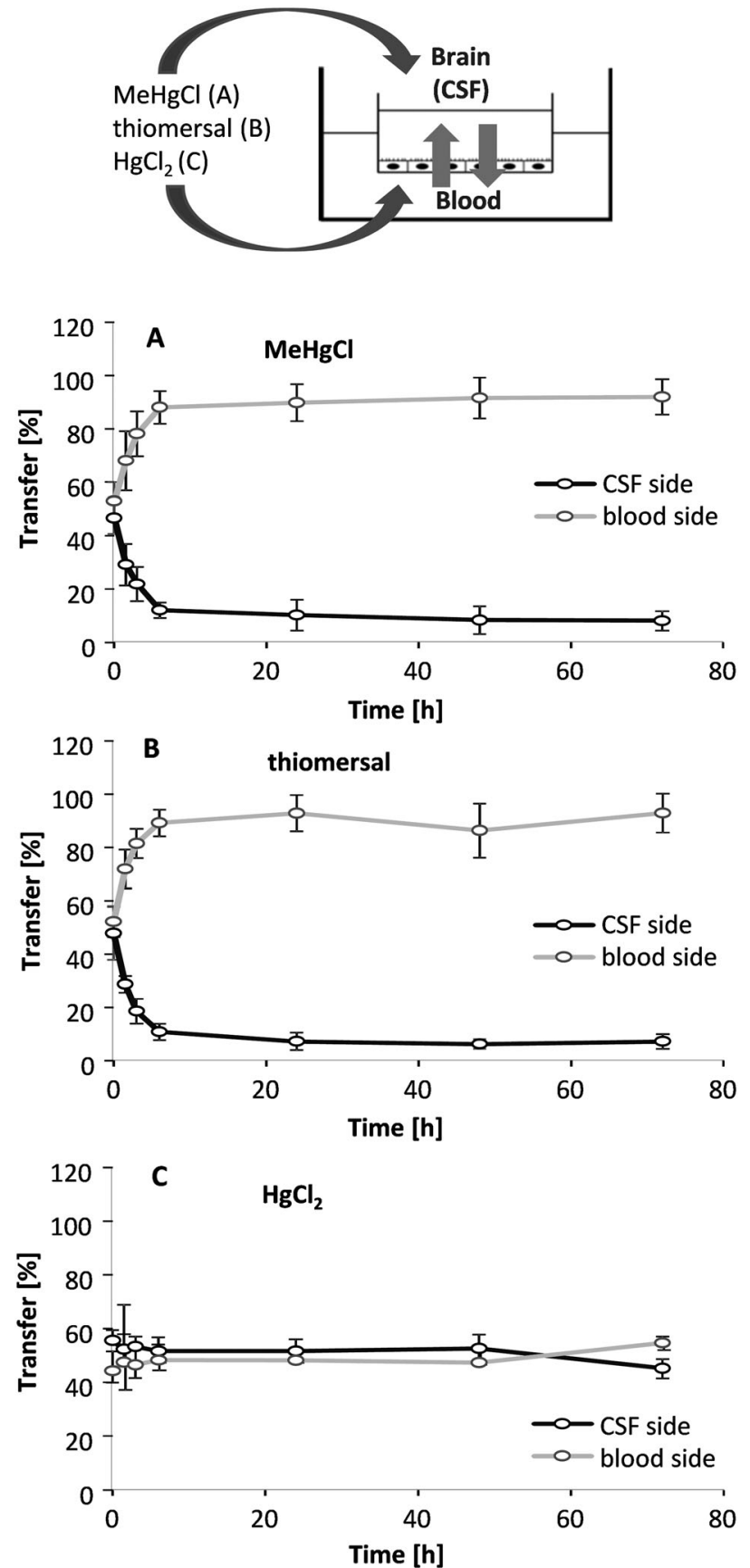

Fig. $8 \mathrm{Hg}$ transfer after incubation with $\mathrm{MeHgCl}(\mathrm{A})$, thiomersal (B) and $\mathrm{HgCl}_{2}$ (C) in the basolateral compartment (blood side) and in the apical compartment (CSF side) simultaneously for $72 \mathrm{~h}$. Data are expressed as \% of the whole mercury amount measured in both compartments. The mercury content was quantified by ICP-MS. Shown are mean values of at least 3 independent cell preparations with 2 independent determinations ( $A$ and $B$ ) or of 1 cell preparation with 3 independent determinations (C) $\pm S D$.

cerebral blood vessels. ${ }^{34}$ Therefore, based on the demonstrated active efflux of $\mathrm{MeHgCl}$ and thiomersal out of the brain, the blood-CSF barrier might prevent the developing brain as well as the adult brain from further neurotoxic damage induced by the mercury compounds.

In summary, these data represent a new approach in the understanding of mercury transfer but also generate new questions, which need to be investigated. Thus, studies to identify the molecular mechanisms behind and the responsible transporter family are necessary. Regarding transfer into/out of other organs than the brain, besides amino acid transporters, members of the OAT family play significant roles in renal uptake of $\mathrm{Hg}^{2+}$ and MeHg. ${ }^{10}$ Llop et al. found an association of the ABC-transporters $\mathrm{ABCB} 1, \mathrm{ABCC} 1$ and $\mathrm{ABCC} 2$ and mercury accumulation in the fetus. ${ }^{35}$ A number of transporters are described for the choroid plexus. ${ }^{36}$ Among these, we selected the OATs and MRPs as well as P-gp (ABCB1) and the breast cancer resistance protein (BCRP, ABCG2) for first inhibition experiments (data not shown). These transporters are expressed in rat choroid plexus albeit subcellular distribution and functional roles are not completely understood. For OAT and P-gp an apical and sub-apical localization was stated, whereas MRP1 was demonstrated to be expressed at the basolateral membrane. ${ }^{36,37}$ Indomethacin as substrate for OAT2 and the MRP family, ${ }^{22,23}$ valspodar representing a P-gp inhibitor ${ }^{38}$ and fumitremorgin $\mathrm{C}$ as ABCG2 inhibitor ${ }^{39}$ did not inhibit the efflux of organic mercury compounds out of the brain. In the rat choroid plexus, LAT1 has been demonstrated to be localized at the basolateral membrane ${ }^{29,30}$ and thus further studies could prove whether LAT1 is also localized on the basolateral membrane of the applied primary porcine blood-CSF barrier model and might contribute to the observed efflux of the organic mercury compounds in the present study.

A further issue is the metabolism of the applied mercury compounds. Carneiro et al. demonstrated a conversion of ethylmercury to inorganic mercury in murine brain tissue within 6 days after exposure to thiomersal. ${ }^{12}$ The dealkylation of $\mathrm{MeHgCl}$ seems not to be as effective as after thiomersal application as reported by Burbacher et al. ${ }^{13}$ However, we could show clear differences between organic and inorganic compounds in the efflux behaviour across the cell culture model of the blood-CSF barrier indicating compounds differences.

\section{Conclusions}

For the first time studies regarding transfer properties as well as effects on the barrier integrity of organic and inorganic mercury compounds within a well-established in vitro model of the bloodCSF barrier were performed. The barrier is much more sensitive towards $\mathrm{MeHgCl}$ and thiomersal as compared to inorganic $\mathrm{HgCl}_{2}$. Transfer from the blood side to the CSF side was low but studies regarding the transfer out of the CSF side strongly indicate an active transport for the organic compounds. The fact that there is a route out of the brain is a new approach in the understanding of mercury compounds dependent transfer and presents a new basis for further research regarding the interaction between mercury compounds and the blood-CSF barrier.

\section{References}

1 WHO, World Health Organization, 2007.

2 K. M. Rice, E. M. Walker, Jr., M. Wu, C. Gillette and E. R. Blough, J. Prev. Med. Public Health, 2014, 47, 74-83. 
3 J. G. Dorea, M. Farina and J. B. Rocha, J. Appl. Toxicol., 2013, 33, 700-711.

4 T. W. Clarkson and L. Magos, Crit. Rev. Toxicol., 2006, 36, 609-662.

5 J. G. Dorea, Neurochem. Res., 2011, 36, 927-938.

6 S. Trumpler, B. Meermann, S. Nowak, W. Buscher, U. Karst and M. Sperling, J. Trace Elem. Med. Biol., 2014, 28, 125-130.

7 M. Aschner and T. W. Clarkson, Brain Res., 1988, 462, 31-39.

8 M. Aschner and T. W. Clarkson, Pharmacol. Toxicol., 1989, 64, 293-297.

9 Z. Yin, H. Jiang, T. Syversen, J. B. Rocha, M. Farina and M. Aschner, J. Neurochem., 2008, 107, 1083-1090.

10 C. C. Bridges and R. K. Zalups, J. Toxicol. Environ. Health, Part B, 2010, 13, 385-410.

11 L. T. Zimmermann, D. B. Santos, A. A. Naime, R. B. Leal, J. G. Dorea, F. Barbosa, Jr., M. Aschner, J. B. Rocha and M. Farina, Neurotoxicology, 2013, 38, 1-8.

12 M. F. Carneiro, J. M. Oliveira Souza, D. Grotto, B. L. Batista, V. C. de Oliveira Souza and F. Barbosa, Jr., Environ. Res., 2014, 134C, 218-227.

13 T. M. Burbacher, D. D. Shen, N. Liberato, K. S. Grant, E. Cernichiari and T. Clarkson, Environ. Health Perspect., 2005, 113, 1015-1021.

14 W. Zheng, Microsc. Res. Tech., 2001, 52, 89-103.

15 W. Zheng, D. F. Perry, D. L. Nelson and H. V. Aposhian, FASEB J., 1991, 5, 2188-2193.

16 W. Zheng, M. Aschner and J. F. Ghersi-Egea, Toxicol. Appl. Pharmacol., 2003, 192, 1-11.

17 M. Nakamura, A. Yasutake, M. Fujimura, N. Hachiya and M. Marumoto, Arch. Toxicol., 2011, 85, 911-918.

18 J. Bornhorst, C. A. Wehe, S. Huwel, U. Karst, H. J. Galla and T. Schwerdtle, J. Biol. Chem., 2012, 287, 17140-17151.

19 S. Angelow, P. Zeni and H. J. Galla, Adv. Drug Delivery Rev., 2004, 56, 1859-1873.

20 M. Haselbach, J. Wegener, S. Decker, C. Engelbertz and H. J. Galla, Microsc. Res. Tech., 2001, 52, 137-152.

21 A. H. Schinkel and J. W. Jonker, Adv. Drug Delivery Rev., 2012, 64, 138-153.

22 Y. Sai, Y. Kato, K. Nakamura, S. Kato, T. Nishimura, Y. Kubo, I. Tamai, S. Yang, Z. Hu, I. Yamada and A. Tsuji, J. Pharm. Sci., 2006, 95, 336-347.
23 H. Luna-Munguia, J. D. Salvamoser, B. Pascher, T. Pieper, T. Getzinger, M. Kudernatsch, G. Kluger and H. Potschka, J. Pharmacol. Exp. Ther., 2015, 352, 368-378.

24 C. A. Wehe, I. Pieper, M. Holtkamp, G. M. Thyssen, M. Sperling, T. Schwerdtle and U. Karst, Anal. Bioanal. Chem., 2014, 406, 1909-1916.

25 J. S. de Gois and D. L. G. Borgesa, J. Braz. Chem. Soc., 2014, 25, 1601-1606.

26 P. M. Cummins, Mol. Cell. Biol., 2012, 32, 242-250.

27 M. T. Jenssen, A. L. Brantsaeter, M. Haugen, H. M. Meltzer, T. Larssen, H. E. Kvalem, B. E. Birgisdottir, Y. Thomassen, D. Ellingsen, J. Alexander and H. K. Knutsen, Sci. Total Environ., 2012, 439, 220-229.

28 M. Aschner and J. L. Aschner, Neurosci. Biobehav. Rev., 1990, 14, 169-176.

29 R. Duelli, B. E. Enerson, D. Z. Gerhart and L. R. Drewes, J. Cereb. Blood Flow Metab., 2000, 20, 1557-1562.

30 L. M. Roberts, D. S. Black, C. Raman, K. Woodford, M. Zhou, J. E. Haggerty, A. T. Yan, S. E. Cwirla and K. K. Grindstaff, Neuroscience, 2008, 155, 423-438.

31 EFSA, EFSA J., 2012, 10, 1-241.

32 M. Farina, D. S. Avila, J. B. da Rocha and M. Aschner, Neurochem. Int., 2013, 62, 575-594.

33 P. Grandjean and P. J. Landrigan, Lancet, 2006, 368, 2167-2178. 34 S. A. Liddelow, S. Temple, K. Mollgard, R. Gehwolf, A. Wagner, H. Bauer, H. C. Bauer, T. N. Phoenix, K. M. Dziegielewska and N. R. Saunders, PLoS One, 2012, 7, e33554.

35 S. Llop, K. Engstrom, F. Ballester, E. Franforte, A. Alhamdow, F. Pisa, J. S. Tratnik, D. Mazej, M. Murcia, M. Rebagliato, M. Bustamante, J. Sunyer, A. Sofianou-Katsoulis, A. Prasouli, E. Antonopoulou, I. Antoniadou, S. Nakou, F. Barbone, M. Horvat and K. Broberg, PLoS One, 2014, 9, e97172.

36 D. S. Miller, S. Lowes and J. B. Pritchard, in The BloodCerebrospinal Fluid Barrier, ed. W. Zheng and A. Chodobski, Taylor and Francis Group, Boca Raton, 2005, pp. 147-167.

37 S. Choudhuri, N. J. Cherrington, N. Li and C. D. Klaassen, Drug Metab. Dispos., 2003, 31, 1337-1345.

38 S. Kunimatsu, T. Mizuno, M. Fukudo and T. Katsura, Drug Metab. Dispos., 2013, 41, 1592-1597.

39 R. W. Robey, B. Lin, J. Qiu, L. L. Chan and S. E. Bates, J. Pharmacol. Toxicol. Methods, 2011, 63, 217-222. 